\title{
Deceptive behaviour of Colletotrichum truncatum: strategic survival as an asymptomatic endophyte on non-host species
}

\author{
Nalika Priyanwada Ranathunge*, Hewa Bajjamage Pavithra Sandani
}

Department of Agricultural Biology, Faculty of Agriculture, University of Ruhuna, Mapalana, 81100 Kamburupitiya, Sri Lanka

Received: November 6, 2015

Accepted: May 20, 2016

\begin{abstract}
Colletotrichum truncatum (syn. C. capsici), like many other members of the genus Colletotrichum, displays a highly developed infection mechanism against a number of agriculturally important crops. Among many survival strategies, $C$. truncatum is well known for its wide host range and high pathogenicity on several major crop species. Meticulous understanding of a pathogen's infection mechanisms is the best way to achieve successful management of a disease. This study was carried out to evaluate the pathogenicity of C. truncatum on selected crop plants and weed species and to detect the possibility of non-host species to facilitate survival of the pathogen. Inoculation of an isolate of C. truncatum to four crops: curry chilli - Capsicum annuum (var. CA8), eggplant - Solanum melongena (var. Lena Iri), tomato - Solanum lycopersicum (var. Thilina) and green chilli - C. annuum (var. KA2) and three weed species: little ironweed (Vernonia cinerea), billygoat-weed (Ageratum conyzoides) and Bengal dayflower (Commelina benghalensis) resulted in approximately 3.5 disease severity (DS) (100\% disease incidence-DI) on S. lycopersicum and C. annuum (var. KA2), followed by 2.8 and 1.8 DS (100\%, 75\% DI) on C. annuum (var. CA8) and S. melongena (var. Lena Iri), respectively. The three weed species were completely symptomless up to 8 weeks after the inoculation (WAI). However, microscopic studies and serial culturing of the inoculated tissues revealed the presence of the fungus in all the tested plants. Appressoria were present in all treated leaves and eventually broke their dormancy upon leaf senescence nearly 6 WAI. This study reveals the potential of C. truncatum infecting all tested crops and the capability of the three weed species in harboring the pathogen asymptomatically for several weeks. Thus, early management of inoculum in the field is suggested for $C$. truncatum diseases.
\end{abstract}

Key words: asymptomatic survival, Colletotrichum truncatum, non-host species, pathogenicity

\section{Introduction}

Colletotrichum truncatum (previously known as C. capsici) (Damm et al. 2009) is a notorious pathogen of many agriculturally important crops such as chillies, cowpea, cotton, tomato, soybean, lentil and Piper spp. (Emechebe 1981; Roberts and Snow 1984; Pring et al. 1995; Than et al. 2008; Gossen et al. 2009). It is known to be a subcuticular intramural necrotrophic pathogen, giving least opportunity for induced host responses (Roberts and Snow 1990; Zakaria 1990). This feature has given C. truncatum the advantage of infecting a wide range of hosts, thus $C$. truncatum has the potential to infect a wide variety of crop plants as well as weed species (Pring et al. 1995).

Proper understanding of the infection mechanism and the disease cycle of a pathogen can help to achieve successful disease management in the field. One of the key events in a pathogen's life cycle is its survival during the off seasons and non-fruit bearing periods of a crop. The occurrence of alternative host species has been reported in many other Colletotrichum species (Freeman et al. 2001) includinga few reports of $C$. truncatum survival on other field crops as well as on weed species (Boyette 1991). While the degree of virulence among different strains of the pathogen can vary among different hosts (Gossen et al. 2009; Montri et al.
2009), in some situations, C. truncatum is known to exist as an asymptomatic endophyte through non-pathogenic relationships developed with non-host plants (Perfect et al. 1999). This adaptation is obviously a survival strategy of the fungus, which might lead to successful spore production on the particular plant. Understanding potential inoculum sources is highly important in employing agronomic and cultural management practices such as proper weed control and prudent crop rotation.

One of the striking features of the genus Colletotrichum is that, some of its members have the ability to spend a quiescent life stage on a living tissue. Colletotrichum truncatum particularly displays the ability to colonize and subsequently to spend a dormant phase on its well-known hosts (e.g. Pring et al. 1995; Ranathunge et al. 2012), and on unknown weed hosts (McLean and Roy 1991). Therefore, the crops that are usually intercropped/rotated with the known susceptible hosts have to be studied for their potential for harboring the pathogen in an asymptomatic state even though they have never been reported to express anthracnose disease symptoms. Furthermore, due to rapid pathogen evolution, new strains with higher virulence levels can possibly arise, which can lead to unexpected epidemics leading to severe infections destroying crops. 
In addition, there are many weed species that can serve as possible hosts of the pathogen. Based on the speculations of Mordue (1971) and the work of McLean and Roy (1991), certain weeds act as potential reservoirs of inoculum of C. truncatum. Inoculation experiments conducted under greenhouse conditions with nine different subtropical weed species showed that all the isolates obtained from these weed species were pathogenic on tomato fruits. Further study revealed that none of the weed isolates caused any symptoms on the weed host species, however, each was re-isolated onto culture media. Interestingly, each isolate produced fertile acervuli on seedlings that had been killed by the herbicide, paraquat (1,1'-dimethyl-4-4'-bipyridinium dichloride) (McLean and Roy 1991).

Therefore, the possibility of the existence of alternative hosts of $C$. truncatum under local conditions should also be taken into consideration. The aims of this study were to evaluate the pathogenicity of $C$. truncatum on selected crop plants and weed species and to determine the possibility of these unidentified host species to facilitate asymptomatic survival of the pathogen.

\section{Materials and Methods}

\section{The pathogen}

Colletotrichum truncatum (isolate CCKM1) was isolated from an infected chilli fruit collected from the Kamburupitiya area of the Sothern Province of Sri Lanka and was cultured on Potato Dextrose Agar (PDA). The isolate was identified by spore morphology (Shenoy et al. 2007; Damm et al. 2009) and a single-spore culture was maintained on PDA at $4^{\circ} \mathrm{C}$.

For the preparation of the spore suspension, two week old sporulating C. truncatum colonies on PDA plates were covered with approximately $10 \mathrm{ml}$ of sterilized distilled water and gently scraped with a sterile needle. The collected spore suspension was filtered into a conical flask through two layers of sterile cheese cloth. The suspension was then slightly shaken to separate spore clusters and the spore concentration was adjusted to $10^{6}$ spores $\cdot \mathrm{ml}^{-1}$ with sterile distilled water after counting the spores using a heamocytometer.

\section{Plant material}

Four vegetable species: curry chilli - Capsicum annuum L. (var. CA8), eggplant - Solanum melongena L. (var. Lena Iri), tomato - Solanum lycopersicum L. (var. Thilina), and green chilli - C. annuum (var. KA2) and three weed species: little ironweed (Vernonia cinerea L.), billygoat-weed (Ageratum conyzoides L.) and Bengal dayflower (Commelina benghalensis L.) were grown in pots under greenhouse conditions at $27^{\circ} \mathrm{C}$ and 12 day/night cycles.

\section{Inoculation and incubation of treated plants}

Four week old plants were sprayed with a freshly prepared spore suspension $\left(10^{6}\right.$ spores $\left.\cdot \mathrm{ml}^{-1}\right)$ of the C. truncatum isolate (CCKM1) up to the point of runoff. The ex- periment was conducted with four replicates under completely randomized design. All the fully opened leaves present at the time of spraying were tagged for future observations. A controlled experiment was carried out for each plant species where plants were sprayed with sterile distilled water in the same manner. The inoculated plants were covered with polythene to provide $100 \%$ humidity for $72 \mathrm{~h}$ and then transferred to a greenhouse.

\section{Observations and measurements}

Plants were regularly observed for the appearance of symptoms for 8 weeks. Disease incidence (DI) and disease severity (DS) was measured on infected plants. Disease incidence was calculated as the percent of plants that expressed visible symptoms over the total number of plants used for each treatment. For severity determination, the following formula by Hartman et al. (1986) was used: 1 = no symptoms; 2 = slight veinal or leaf necrosis; 3 = veinal and petiole necrosis; $4=$ veinal necrosis, petiole and stem cankering; and $5=$ death of plant.

To observe the endophytic colonization, samples of asymptomatic tissues (four inoculated leaves from each replicate) were surface sterilized with $2 \%$ sodium hypochlorite (chlorox) for $5 \mathrm{~min}$, followed by washing in sterile distilled water three times and the tissues were aseptically excised into approx. $5 \mathrm{~mm}^{2}$ squares and cultured on PDA at two-week intervals. The plates were incubated at $27^{\circ} \mathrm{C}$ and 12 day/night cycles. The number of surface sterilized leaf tissues from which the pathogen could be recovered on PDA was counted three days after culturing. Identities of the resulting cultures were confirmed with the original isolate for colony and spore morphology.

\section{Microscopic observations}

The samples containing eight samples of treated leaf tissues from each plant species were collected weekly from one to 6 weeks after inoculation (WAI). Approximately $1 \mathrm{~cm}^{2}$ pieces were excised and placed in a clearing solution of $1: 2$ (absolute ethanol : acetic acid) for $24 \mathrm{~h}$ to remove chlorophyll (Curry et al. 2002), followed by a replacement with a fresh clearing solution of the same composition for another $24 \mathrm{~h}$. The cleared tissues were then washed with distilled water, blot dried, stained with an aniline blue solution and mounted on a microscopic slide in a drop of water. Tissues were observed under the light microscope (Carl Zeiss, Axi Lab. A1, Germany).

\section{Data analysis}

All the data were subjected tothe ANOVA procedure followed by mean separation (Duncan's) using IBM SPSS 22.0.0.0 software (IBM Corporation, Armonk, NY).

\section{Results}

Out of all the treated plants, tomato (var. Thilina) (100\% DI, 3.5 DS) and green chilli (var. CA8) (100\% DI, 3.6 DS) produced characteristic anthracnose lesions on their leaves, petioles and stems (Table 1; Figs. 1A-B). 
Table 1. Disease incidence (DI) and disease severity (DS) ratings on plants 2 weeks after inoculation with Colletotrichum truncatum

\begin{tabular}{lcc}
\hline \multicolumn{1}{c}{ Plant spp. } & DI [\%] & DS \\
\hline Capsicum annuum (var. CA8) & $100 \mathrm{~b}$ & $3.6 \mathrm{c}$ \\
Solanum melongena & $75 \mathrm{~b}$ & $1.8 \mathrm{ab}$ \\
Solanum lycopersicum & $100 \mathrm{~b}$ & $3.5 \mathrm{c}$ \\
Capsicum annuum (var. KA2) & $100 \mathrm{~b}$ & $2.8 \mathrm{~b}$ \\
Vernonia cinerea & $0 \mathrm{a}$ & $1.0 \mathrm{a}$ \\
Ageratum conyzoides & $0 \mathrm{a}$ & $1.0 \mathrm{a}$ \\
Commelina benghalensis & $0 \mathrm{a}$ & $1.0 \mathrm{a}$ \\
Control & $0 \mathrm{a}$ & $1.0 \mathrm{a}$ \\
\hline
\end{tabular}

Values within each column followed by the same letter are not significantly different according to Duncan's Multiple Range test at $\mathrm{p}<0.001$

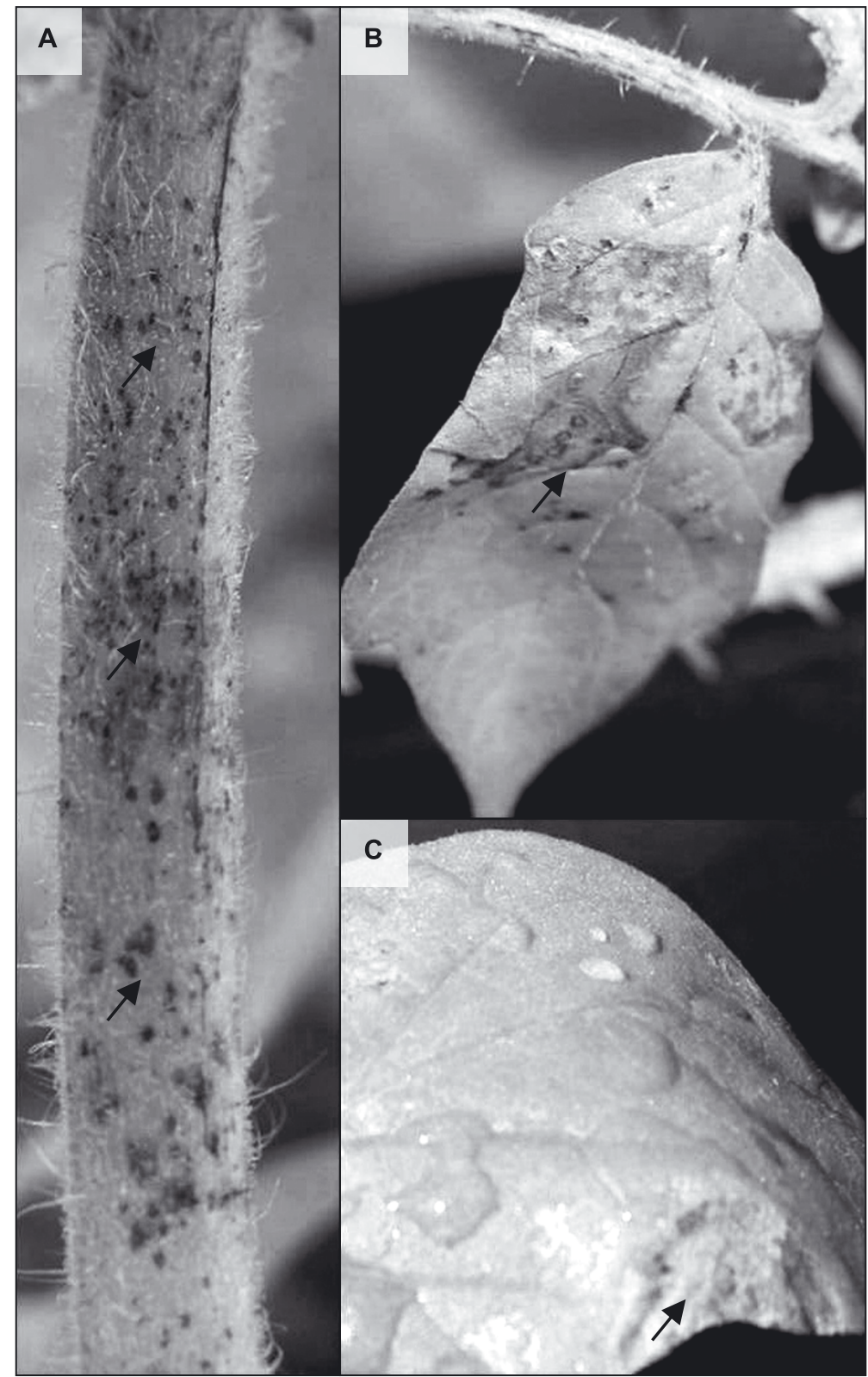

Fig. 1. Appearance of anthracnose symptoms (arrow heads) on plants inoculated with Colletotrichum truncatum: A-on tomato stems; B - on tomato leaves; C - on eggplant leaves at 10 days after inoculation (DAI). The leaves were totally symptomless at the green phase except for one or two scattered, unexpanded blotches that appeared few days after inoculation 
Table 2. Mean number of symptomless plants (4 replicates; 4 leaves from each replicate) from which, the pathogen (Colletotrichum truncatum) could be recovered on PDA media on biweekly basis

\begin{tabular}{lllll}
\hline \multirow{2}{*}{ Name of the plant } & \multicolumn{4}{c}{ Mean number of plants* } \\
\cline { 2 - 5 } & \multicolumn{1}{c}{2 WAI } & 4 WAI & 6 WAI & 8 WAI \\
\hline Capsicum annuum (var. CA8) & $3.75 \pm 0.25 \mathrm{ab}$ & $3.50 \pm 0.29 \mathrm{ab}$ & $2.75 \pm 0.63 \mathrm{ab}$ & $3.00 \pm 0.41 \mathrm{ab}$ \\
Solanum melongena & $4.00 \pm 0.00 \mathrm{a}$ & $2.75 \pm 0.25 \mathrm{ab}$ & $3.25 \pm 0.48 \mathrm{ab}$ & $2.00 \pm 0.41 \mathrm{bc}$ \\
Solanum lycopersicum & $3.50 \pm 0.29 \mathrm{ab}$ & $3.50 \pm 0.29 \mathrm{ab}$ & $2.50 \pm 0.29 \mathrm{ab}$ & $2.00 \pm 0.71 \mathrm{bc}$ \\
Capsicum annuum (var. KA2) & $4.00 \pm 0.00 \mathrm{a}$ & $3.75 \pm 0.25 \mathrm{a}$ & $3.00 \pm 0.41 \mathrm{a}$ & $3.50 \pm 0.29 \mathrm{a}$ \\
Vernonia cinerea & $1.00 \pm 0.41 \mathrm{~d}$ & $1.25 \pm 0.48 \mathrm{c}$ & $1.00 \pm 0.00 \mathrm{c}$ & $1.50 \pm 0.50 \mathrm{c}$ \\
Ageratum conyzoides & $2.50 \pm 0.29 \mathrm{c}$ & $2.50 \pm 0.65 \mathrm{~b}$ & $2.50 \pm 0.50 \mathrm{~b}$ & $2.50 \pm 0.50 \mathrm{abc}$ \\
Commelina benghalensis & $3.00 \pm 0.41 \mathrm{bc}$ & $3.00 \pm 0.4 \mathrm{ab}$ & $2.25 \pm 0.25 \mathrm{ab}$ & $2.00 \pm 0.41 \mathrm{bc}$ \\
\hline
\end{tabular}

*means \pm standard errors within a column followed by the same letter do not differ significantly between plant types according to Fisher's least significant difference test at $\mathrm{p}<0.05$. No infection was detected on the control plants

WAI - weeks after inoculation; PDA - Potato Dextrose Agar

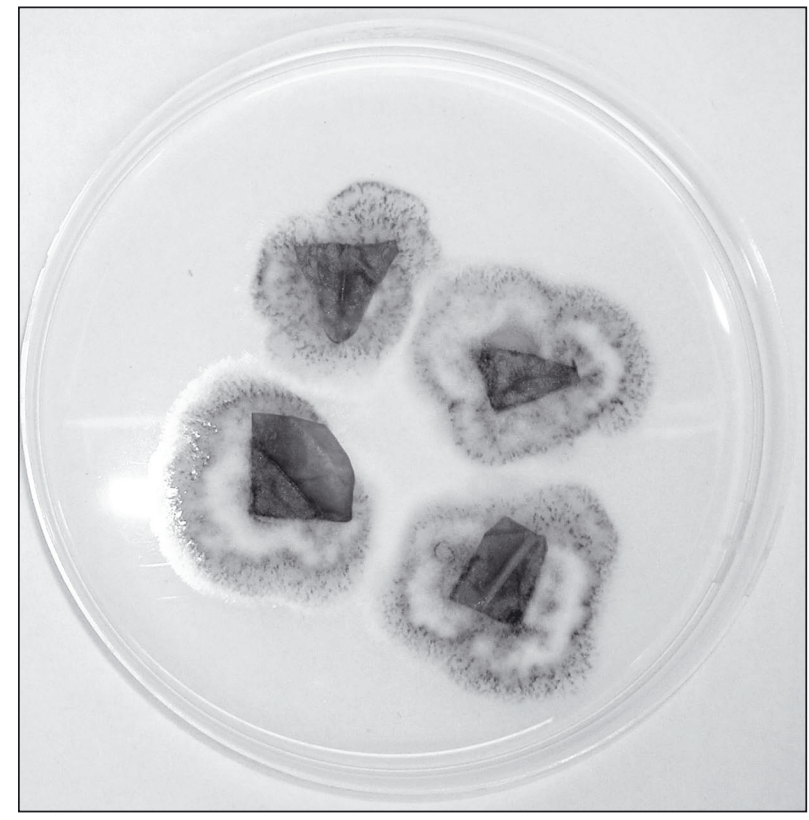

Fig. 2. Emergence of endophytic Colletotrichum truncatum mycelium from inoculated, symptomless leaves of Capsicum annuum [4 weeks after inoculation (WAI)] on Potato Dextrose Agar (PDA) medium 3 days after culturing

Colletotrichum truncatum was recovered from the symptomatic plant parts (leaves and petioles) on PDA media. All the other plants were symptomless except 1-2 small anthracnose lesions on eggplant (var. Lena Iri) (Fig. 1C) (75\% DI, 1.8 DS) and curry chilli (var. KA2) (100\% DI, 2.8 DS). All the treated plants continued their normal growth and development similar to the untreated controls for the tested period. Green chilli plants produced typical anthracnose symptoms on ripened fruits approximately 8 WAI. None of the other plants produced anthracnose symptoms on their fruits during the period the research was conducted (up to $8 \mathrm{WAI}$ ).

Culturing of asymptomatic leaves on PDA at biweekly intervals revealed the presence of the pathogens in all seven plant species up to 8 WAI (Table 2; Fig. 2). Based on colony and spore morphology they all were identified as $C$. truncatum isolate when compared with a culture of the original isolate. Overall results revealed that, $50-100 \%$ leaf tissues of six of the tested plant species showed pathogen recovery. However, with respect to $V$. cinerea, only a $35 \%$ recovery rate was observed.

Microscopic observation of samples at 1-6 WAI revealed that, appressoria formation occurred in all plant species within the first week of inoculation. However, further colonization events were not observed in the subsequent weeks. Some of the appressoria remained attached to the germ tube and spore throughout the time, while in some cases the spore was physically detached. Approximately during 5-6 WAI, some of the treated leaves reached senescence and samples taken from those revealed the dormancy breakage (Fig. 3). Formation of infection hyphae (image not shown) and secondary appressoria (Fig. 3) were clearly observed on chilli (var. CA8) from the samples taken at 6 WAI.

\section{Discussion}

There are many reports of pathogenic Colletotrichum species that show non-pathogenic relationships with plants (Bayman et al. 1997; Photita et al. 2005; Santamaria and Bayman 2005). Some species of Colletotrichum such as C. gloeosporioides, C. acutatum, and C. magna, are described as pathogens of a single host and asymptomatic endophytes of other species (Perfect et al. 1999). Thus it is clear that members of Colletotrichum species are capable of adapting to different strategies depending on the host availability. Furthermore, it has been emphasized that, the ability to cause disease and the ability to colonize host tissue seem to be separate traits in such fungi (Jansen et al. 2005). This study suggests that $C$. truncatum presents a similar behavior in non-host plants. According to Ranathunge et al. (2012), a quiescent stage of C. truncatum has been observed in chilli foliage, which shows that the pathogen can remain symptomless even on the susceptible host for some time. However when the opportunity presents itself, it continues to grow and invade the host tissues expressing the disease. This dormant nature of C. truncatum was confirmed in the present study with respect to all examined species. However, periodical culturing of inoculated tissues revealed the presence of the pathogen for several 

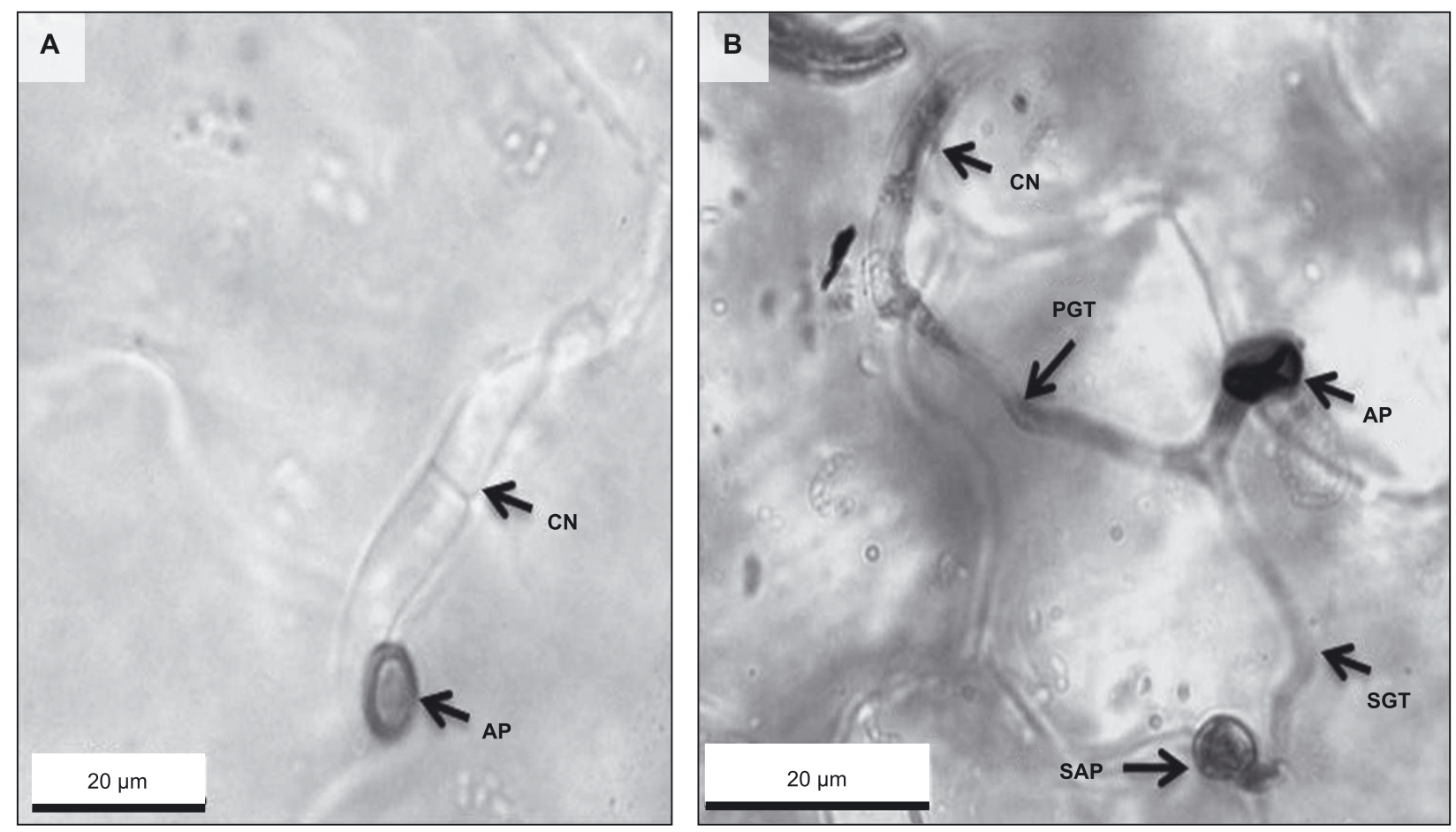

Fig. 3. Two light micrographs showing evidence of Colletotrichum truncatum appressorial formation: A - 1 week after inoculation (WAI) and dormancy breakage; B - 6 WAI on cleared Capsicum annuum leaf tissues. Note the development of a secondary germ tube (SGT) and secondary appressoria (SAP) that was originated from a primary appressorium (AP); CN - conidium, PGT primary germ tube

weeks, which indicates that all the tested plant species have the ability to harbor the pathogen and might serve as sources of inocula for C. truncatum.

In conclusion, we propose that $C$. truncatum inocula have the ability to survive on symptomless leaves, and that the production of conidia at senescence may increase inoculum for the next round of infection. A greater awareness of the unrevealed fungal dynamics on symptomless plants may also justify changes in currently recommended control strategies. Early fungicide applications, for example, might effectively reduce initial inoculum production on developing plants, thereby reducing subsequent epidemic development on susceptible crops.

\section{Acknowledgements}

Authors are grateful to the University Ruhuna for the financial support.

\section{References}

Bayman P., Lebron L.L., Tremblay R.L., Lodge D.J. 1997. Variation in endophytic fungi from roots and leaves of Lepanthes (Orchidaceae). New Phytologist 135: 143-149.

Boyette C.D. 1991. Host range and virulence of Colletotrichum truncatum, a potential mycoherbicide for hemp sesbania (Sesbania exaltata). Plant Disease 75 (1): 62-64.

Curry K.J., Abril M., Avant J.B., Smith B.J. 2002. Strawberry anthracnose: Histopathology of Colletotrichum acutatum and C. fragariae. Phytopathology 92 (10): 1055-1063.
Damm U., Woudenberg J.H.C., Cannon P.F., Crous P.W. 2009. Colletotrichum species with curved conidia from herbaceous hosts. Fungal Diversity 39: 45-87.

Emechebe A.M. 1981. Brown blotch of cowpea in North Nigeria. Samaru Journal of Agricultural Research 1: 20-26.

Freeman S., Horowitz S., Sharon A. 2001. Pathogenic and nonpathogenic lifestyles in Colletotrichum acutatum from strawberry and other plants. Phytopathology 91 (10): 986-992.

Gossen B.D., Anderson K.L., Buchwaldt L. 2009. Host specificity of Colletotrichum truncatum from lentil. Canadian Journal of Plant Pathology 31 (1): 65-73.

Hartman G.L., Manandhar J.B., Sinclair J.B. 1986. Incidence of Colletotrichum spp. on soybeans and weeds in Illinois and pathogenicity of Colletotrichum truncatum. Plant Disease 70 (8): 780-782.

Jansen C.D., Wettstein V., Schafer W., Kogel K.H., Felk A., Maier F.J. 2005. Infection patterns in barley and wheat spikes inoculated with wild-type and trichodiene synthase gene disrupted Fusarium graminearum. Proceedings of the National Academy of Science, USA 102 (46): 16892-16897.

McLean K.S., Roy K.W. 1991. Weeds as a source of Colletotrichum capsici causing anthracnose on tomato fruit and cotton seedlings. Canadian Journal of Plant Pathology 13 (2): 131-134.

Montri P., Taylor P.W.J., Mongkolporn O. 2009. Pathotypes of Colletotrichum capsici, the causal agent of chilli anthracnose, in Thailand. Plant Disease 93: 17-20.

Mordue J.E.M. 1971. CMI descriptions of pathogenic fungi and bacteria Nos 315, 316, 317.

Perfect S.E., Hughes H.B., O'Connel R.J., Green J.R. 1999. Colletotrichum: A model genus for studies on pathology and 
fungal-plant interactions. Fungal Genetics and Biology 27 (2-3): 186-198.

Photita W., Taylor P.W.J., Ford R., Hyde K.D., Lumyong S. 2005. Morphological and molecular characterization of Colletotrichum species from herbaceous plants in Thailand. Fungal Diversity 18: 117-133.

Pring R.J., Nash C., Zakaria M., Bailey J.A. 1995. Infection process and host range of Colletotrichum capsici. Physiological and Molecular Plant Pathology 46 (2): 137-152.

Ranathunge N.P., Mongkolporn O., Ford R., Taylor P.W.J. 2012. Colletotrichum truncatum pathosystems on Capsicum spp.: infection, colonization and defense mechanisms. Australasian Plant Pathology 41 (5): 463-473.

Roberts R.G., Snow J.P. 1984. Histopathology of cotton boll rot caused by Colletotrichum capsici. Phytopathology 74:390-397.

Robert R.G., Snow J.P. 1990. Morphological and pathological studies of Colletotrichum capsici and C. indicum. Mycologia 82 (1): 82-90.
Santamaria J., Bayman P. 2005. Fungal epiphytes and endophytes of coffee leaves (Coffea arabica). Microbial Ecology 50: 1-8.

Shenoy B.D., Jeewon R., Lam W.H., Bhat D.J., Than P.P., Taylor W.J., Hyde K.D. 2007. Morpho-molecular characterisation and epitypification of Colletotrichum capsici (Glomerellaceae, Sordariomycetes), the causative agent of anthracnose in chilli. Fungal Diversity 27: 197-211.

Than P.P., Jeewon R., Hyde K.D., Pongsupasamit S., Mongkolporn O., Taylor P.W.J. 2008. Characterization and pathogenicity of Colletotrichum species associated with anthracnose on chilli (Capsicum spp.) in Thailand. Plant Pathology 57 (3): 562-572.

Zakaria M. 1990. Diseases of forest plantation species in Peninsular Malaysia. p. 94-99. In: Proceedings of the International Union of Forest Research (IUFRO) workshop on pests and diseases of forest plantations in the Asia-Pasific region. Bangkok, Thailand, 5-11 June 1988. 